\title{
TEKNOLOGI AKUAPONIK APUNG TERINTEGRASI BUDIDAYA IKAN NILA DI DESA KAPU KABUPATEN LOMBOK UTARA
}

\author{
Bagus Dwi Hari Setyono*), Andre Rachmat Scabra \\ Program Vokasi Unram, PDD Lombok Utara \\ Jalan Raya Tanjung-Kayangan, Kabupaten Lombok Utara \\ ${ }^{*}$ Alamat korespondensi: bagus.unram@gmail.com
}

\begin{abstract}
ABSTRAK
Desa Kapu Kabupaten Lombok Utara memiliki potensi perikanan yang cukup baik. Hal tersebut dapat dilihat dari banyaknya sumber mata air yang dapat digunakan untuk keperluan pertanian dan perikanan tersebut. Salah satu pemanfaatan sumber air oleh para masyarakat adalah sebagai media budiadaya ikan air tawar, yaitu ikan nila. Ikan nila telah dipelihara oleh masyarakat Desa Kapu dan menjadi mata pencaharian sampingan. Pendapatan masyarakat melalui kegiatan budidaya ikan nila ini cukup baik mengingat teknologi yang digunakan adalah teknologi semi intensif. Kegiatan pengabdian ini dilakukan agar pendapat masyarakat terhadap budiaday ikan nila menjadi semakin meningkat. Mudahmudahan dapata menjadi mata pencahaian utama bagi mereka. Untuk mensukseskan kegiatan ini, maka kami membuat pelatihan dalam bentuk penyuluhan tentang teknologi akuaponik yang terintegrasi dengan budidaya ikan nila. Hasil dari kegiatan ini cukup baik, yaitu meningkatnya penghasilan masyarakat yang semula hanya bisa panen ikan nila, maka sekarang bisa panen sayur sayuran berjenis pokcoi, bayam, kangkung, dan lain-lain.
\end{abstract}

Kata kunci: budidaya ikan nila, akuaponik, sayur-sayuran, Desa Kapu

\section{PENDAHULUAN}

Budidaya ikan merupakan salah satu aktivitas memenuhi kebutuhan pangan dari sektor perikanan. Dalam satu dekade terakhir, produksi perikanan dari sektor akuakultur mengalami peningkatan sedangkan produksi perikanan hasil penangkapan (captured fishery) cenderung stagnan bahkan mengalami penurunan
(Anonim, 2004). Hal tersebut mengindikasikan bahwa perkembngan sektor budidaya perikanan lebih tinggi dibandingkan dengan sektor penangkapan.

Kualitas air merupakan faktor yang sangat penting dalam keberhasilan kegiatan pemeliharaan ikan, karena akan menentukan hasil yang diperoleh. Kondisi kualitas air juga berperan dalam menekan terjadinya peningkatan 
perkembangan bakteri patogen dan parasit di dalam media pemeliharaan. Sebagai tempat hidup ikan, kualitas air sangat dipengaruhi oleh faktorfaktor fisika dan kimia air seperti suhu, oksigen terlarut, $\mathrm{pH}$, amonia, nitrit dan nitrat (Forteath et al., 1993).

Salah satu upaya yang dapat dilakukan untuk menanggulangi permasalahan di atas adalah dengan mengaplikasikan system resirkulasi akuakultur (Recirculation Aquaculture System) (Suantika, 2001). Sistem ini menggunakan teknik akuakultur dengan kepadatan tinggi di dalam ruang tertutup (indoor), sertakondisi lingkungan yang terkontrol sehingga mampu meningkatkan produksi ikan pada lahan dan air yang terbatas, meningkatkan produksi ikan sepanjang tahun, fleksibilitas lokasi produksi, pengontrolan penyakit dan tidak tergantung pada musim (Tetzlaff dan Heidinger, 1990).

$$
\text { Penggunaan sistem }
$$

resirkulasi pada akuakultur, dapat memberikan keuntungan yaitu memelihara lingkungan kultur yang baik pada saat pemberian pakan untuk pertumbuhan ikan secara optimal. Kelebihan sistem resirkulasi dalam mengendalikan, memelihara dan mempertahankan kualitas air menandakan bahwa sistem resirkulasi memiliki hubungan yang erat dengan proses perbaikan kualitas air dalam pengolahan air limbah, terutama dari aspek biologisnya (Akbar, 2003). Salah satu bentuk penerapan sistem resirkulasi adalah dengan menggunakan sistem budidaya akuaponik, yaitu memelihara ikan dengan tanaman dalam satu sistem yang terintegrasi.

Teknologi akuaponik merupakan salah satu alternatif yang dapat diterapkan dalam rangka pemecahan keterbatasan air. Disamping itu teknologi akuaponik juga mempunyai keuntungan lainnya berupa pemasukan tambahan dari hasil tanaman yang akan memperbesar keuntungan para peternak ikan. Aquaponik yaitu memanfaatkan secara terus menerus air dari pemeliharaan ikan ke tanaman dan sebaliknya dari tanaman ke kolam ikan. Inti dasar dari sistem teknologi ini adalah penyediaan air yang optimum untuk masing-masing komoditas dengan memanfaatkan sistem resirkulasi. Sistem teknologi akuaponik ini muncul sebagai jawaban atas adanya permasalahan semakin sulitnya mendapatkan sumber air yang sesuai untuk budidaya ikan, khususnya di lahan yang sempit, akuaponik yang merupakan salah satu teknologi hemat lahan dan air yang dapat dikombinasikan dengan berbagai tanaman sayuran. 
Kegiatan pengabdian kepda masyarak ini bertujuan untuk menerapkan sistem akuaponik pada pemeliharan ikan nila yang telah dilakukan oleh masyarakat. Pemeliharaan ikan nila sistem semi intensf ini diharapkan dalam memberikan manfaat berupa unsur hara yang bisa digunakan sebagai kebutuhan nutrisi bagi tanaman akuaponik. Pada akhir pemeliharaan, masyarakat diharapkan dalam memiliki peningkatan penghasilan yaitu dengan memanen ikan serta sayur-sayuran hasil budidaya sistem akuponik tersebut.

\section{METODE KEGIATAN}

Metode pelaksanaan kegiatan Pengabdian kepada masyarakat dengan mengintegrasikan teknologi akuaponik pada kegiatan budidaya ikan nila yang dilakukan masyarakat dilakukan dengan beberapa tahapan kegiatan, antara lain;

1. Sosialisasi Program

Sosialisasi kegiatan dilakukan pada masyarakat mitra agar mereka mengetahui rencana dan gamabran kegiatan yang akan kami lakukan. Melalui kegiatan sosialisasi program ini, para masyarakat mulai mepersiapkan berbagai hal yang diperlukan untuk keberhasilan program ini, antara lain, memastikan kegiatan budidaya ikan masih berjalan, menentukan kelomok yang akan dijadikan percontohan, menentukan lokasi kegiatan berikutnya, dan lain lain sebagainya yang dianggap perlu.

2. Penyuluhan teknologi akuaponik Pelatihan bagi kelompok masyarakat diberikan agar dapat memperkaya pengetahuan masyarakat tentang akuaponik. Penyuluha ini diharapkan dapat menjadi bekal bagi masyarakat untuk mengelola paket teknologi akuponik yang akan diberikan oleh tim kegiatan pengabdian kepada masyarakat. Teknologi akuaponik yang diaplikasikan adalah teknologi akuaponik sistem terapung yang tidak membutuhkan pipa penguhung antara media dengan penanaman tanaman.

3. Pemberian bantuan paket teknologi akuaponik

Beberapa bantuan paket teknologi akuaponik yang diberikan untuk masyarak desa kapu adalah styrofoam, bibit tanaman, wadah penanaman bibit, bor untuk melubangi styrofoam, bibit ikan nila, pakan ikan nila, dll.

\section{HASIL DAN PEMBAHASAN}

Kegiatan pengabdian berjalan cukup baik. Hal tersebut ditandai dengan banyak masyarakat yang 
ingin ikut terlibat dalam kegiatan pembuatan akuaponik ini. Masyarakat yang terlibat terdiri dari berbagai kalangan, mulai dari anakanak hingga usia dewasa. Pemberian materi diringi dengan tanya jawab yang menarik oleh para peserta. Materi yang diberikan saat penyuluhan antara lain tentang media tanam yang bisa digunakan untuk akuaponik dan pengenalan tentang akuaponik sistem rakit apung. Berikut adalah penjelasan tentang materi yang diberikan kepada masyarakat.

Media tanam yang bisa digunakan dalam kegiatan akuaponik antara lain ijuk, spon, batu kerikil, dan akar pakis. ljuk merupakan salah satu bahan ramah lingkungan yang mudah diperoleh. Pemanfaatan ijuk sebagai filter merupakan metode yang cukup baik untuk menyaring air. ljuk dapat menyaring kotoran halus yang terdapat pada air tanpa memberikan efek samping karena ijuk merupakan bahan alami yang bersumber dari alam (Setiadi, 2014).

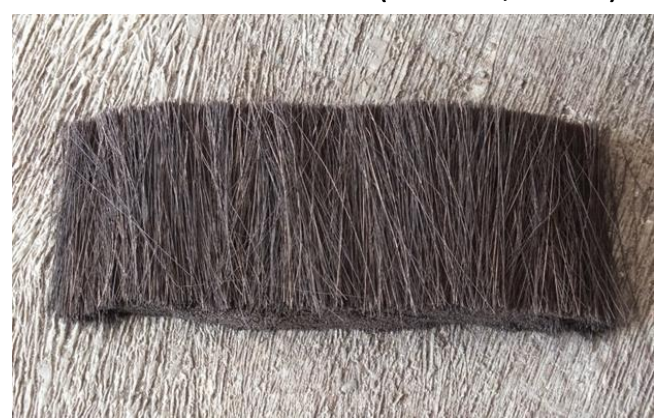

Gambar 1. ljuk Kasar
Spon memiliki tekstur lentur dan pori-pori yang sangat kecil. Dalam penggunaannya sebagai filter, spon harus diberikan treatment terlebih dahulu yakni dengan perendaman dengan air tawar selama beberapa hari. Dengan poripori yang kecil air akan dapat melewati spon dengan baik namun kotoran atau partikel halus akan dapat tersaring dengan baik. Kombinasi dengan beberapa bahan lain akan meningkatkan kemampuan spon dalam menyaring air (Agus, 2001).

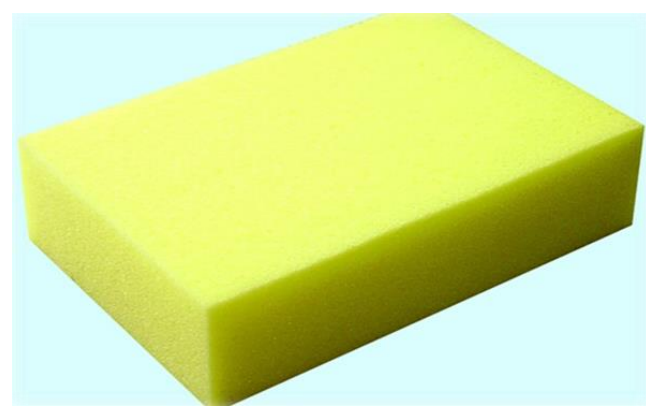

Gambar 2. Spon

Kebutuhan akan air bersih yang semakin tinggi menyebabkan berbagai usaha pemanfaatan bahanbahan murah dan mudah dijumpai sebagai filter semakin banyak dilakukan oleh masyarakat. Semakin tingginya penggunaan air berbanding lurus dengan tingginya limbah yang dihasilkan. Kerikil merupakan bahan yang biasa digunakan dalam kombinasi pembuatan filter. Kerikil merupakan bahan yang termasuk golongan batuan dengan ukuran kecil. Dalam proses filterisasi, kerikil 
berperan dalam menyaring kotoran yang berukuran besar. Selain itu, kerikil juga diketahui dapat menstabilkan suhu air dimana dalam dunia perikanan suhu merupakan faktor yang paling krusial. Dalam sistem akuaponik, kerikil juga dapaat digunakan sebagai media tanam (Agus, 2001).

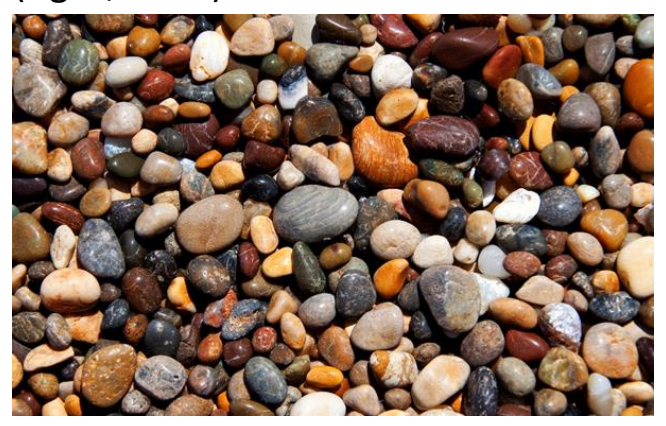

Gambar 3. Kerikil

Akar pakis merupakan salah satu media tanam yang lumrah digunakan dalam budidaya angrek. Akar pakis yang digunakan sebagi media tanam umumnya berasal dari jenis pakis haji. Akar pakis bersifat posporus, artinya akar pakis bersifat lembab saat terkena air, namun tidak dapat menahan air. Kerapatan serat pada akar pakis sebesar 0,85 mikron. Akar pakis tersusun atas holoselulosa dan hemiselulosa tanpa zat kapur, hal ini yang membuat akar pakis lunak namun cepat patah apabila dipadatkan (Setiadi, 2014).

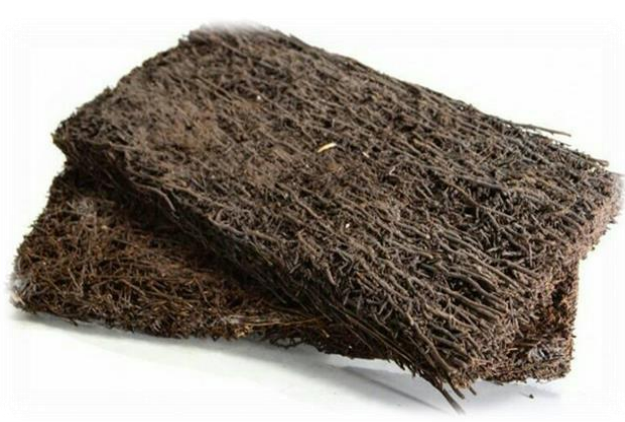

Gambar 4. Akar Pakis

Pada sistem ini larutan nutrisi tidak disirkulasikan, namun dibiarkan tergenang pada bak media atau jika terjadi sirkulasi, cuma dengan aliran rendah, dengan sedikit pergantian air pada lapisan atas. Air / larutan nutrisi dapat digunakan lagi dengan cara mengontrol kepekatan larutan dalam jangka waktu tertentu. Hal ini perlu dilakukan karena dalam jangka yang cukup lama akan terjadi pengkristalan dan pengendapan nutrisi dalam dasar kolam yang dapat mengganggu pertumbuhan tanaman. Tanaman yang bisa diusahakan dengan cara ini adalah sayuran daun, seperti selada, kangkung, bayam, sawi (Anonim, 2014).

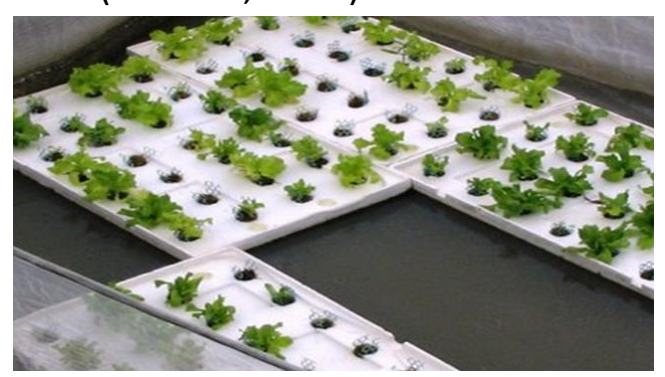

Gambar 5. Sistem Akuaponik Rakit Apung

Floating raft merupakan bagian dari metode deep water culture (DWC), yang menggunakan 
air nutrisi statis untuk mentreat akar secara langsung. DWC selain model rakit apung, bisa juga menggunakan ember-ember yang diisi per ember satu tanaman. Sistem ini mempunyai beberapa karakteristik seperti terisolasinya lingkungan perakaran yang mengakibatkan fluktuasi suhu larutan nutrisi lebih rendah, dapat digunakan untuk daerah yang sumber energi listriknya terbatas karena energi yang dibutuhkan tidak terlalu tergantung pada energi listrik. Dalam kondisi tertentu, sistem pemompaan pada akuaponik diperlukan sebagai bagian sistem resirkulasi air untuk membersihkan sisa feses dan makanan yang tidak termakan (Nugroho et al., 2012).

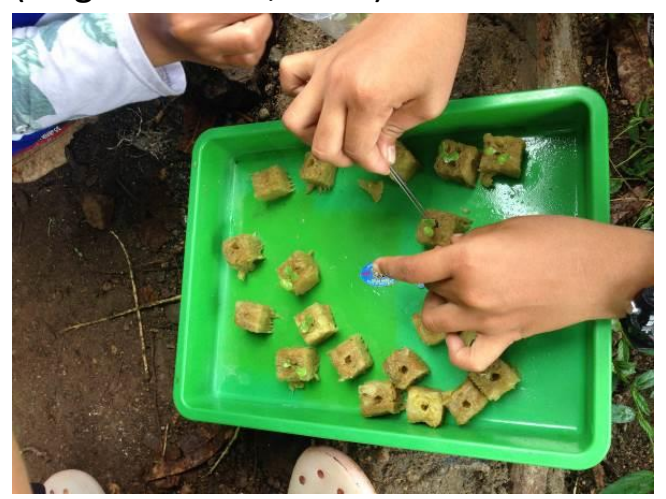

Gambar 6. Proses pembuatan akuaponik sistem apung Tanaman ditancapkan pada lubang dalam styrofoam dengan bantuan busa (agar tanaman tetap tegak) atau memakai netpot. Lapisan styrofom berfungsi sebagai penjepit, isolator panas dan untuk mempertahankan tanaman agar tetap terapung dalam larutan nutrisi.
Agar pemakaian lapisan styrofoam tahan lama biasanya dilapisi oleh plastik mulsa.

Untuk kebutuhan oksigen tanaman mendapatkannya melalui airstone yang diletakkan didalam air. Atau bisa juga dengan memberikan pompa aquarium sehingga air dan larutan nutrisi bisa terus bersirkulasi. Air dan nutrisi yang diberikan akan langsung mengenai akar tanaman secara terus-menerus sehingga tanaman dapat menyerapnya setiap saat. Pada sistem aquaponik ini, kedalaman media harus cukup, setidaknya $30 \mathrm{~cm}$, dikarenakan media akan juga berfungsi sebagai biofilter. Dilapisan air yang bawah terjadi proses nitrifikasi.

Teknologi akuaponik dapat meminimalisr pencemaran air akibat logam berat ataupun limbah nitrogen. Logam berat yang terlarut pada media budidaya ikan dimanfaatkan oleh tanaman melalaui skema phytomining. Logam berat tersebut dikonfersi menjadi bentuk yag lebih sederhana sehingga ia tidak lagi berbahaya bagi ikan. Hasil penelitian Aryanti menunjukkan bahwa tanaman sawi yang digunakan dalam teknologi akuaponik mampu menyerap timbal $\mathrm{Pb}$ ) pada perairan hingga kapasitas 5 ppm. Amonium (NH4+) merupakan limbah nitrogen yang bersifat non toksik, tetapi yang berbentuk tak 
terionisasi (NH3-) bersifat sangat toksik (Kordi dan Tanjung, 2007). Penyerapan amonia dilakukan dengan menggunakan prinsip siklus N. Nitrit akan dirubah menjadi Nitrat dan Nitrat akan dimanfaatkan oleh tanaman sehingga amonia di kolam pemeliharaan akan tereduksi (Dauhan et al., 2014). Royce (2010) menyatakan akuaponik dapat mereduksi amonia dalam bentuk nitrat sebesar $90,6 \%$ dan posfat 37,6 $\%$.

\section{KESIMPULAN}

Kegiatan pengabdian berjaan lancar dan sukses. Masyarakat KLU merasa senang diperhatikan oleh institusi universitas mataram. Mereka berharap kegiatan seperti ini harus lebih sering lagi diadakan.

\section{DAFTAR PUSTAKA}

Agus. 2001. Beberapa Metode Pengelolaan Kualitas Air Tawar. Yogyakarta: Kansius

Anonim, 2014. Mina Sayur (Yumina)

Sebagai Solusi Ketahanan

Pangan di Indonesia. Pusat

Penyuluhan Perikanan

Kementrian Kelautan dan

Perikanan. Jakarta

Aryanti,D.,

Budiono,D,J.,

Rachmawati, F. 2015. Analisis

Struktur Daun Sawi Hijau yang Dipapar Pb. Lentera Bio Vol 3

(1): $37-42$
Dauhan, Riska Emilia Sartika.,Efendi, Eko., Suparmono. 2014. Efektifitas Sistem Akuaponik Dalam Mereduksi Amoniak Dalam Budidaya Ikan. E-Jurnal Rekayasa Dan Teknologi Vol 3 (1) : $297-302$.

Kordi M.G dan Tanjung A.B. 2007.Pengelolaan Kualitas Air dalam Budidaya Perairan. Rineka Cipta. Jakarta.

Nugroho, Ristiawan Agung ., Prambudi, Lilit Teguh., Chilmati., Haditomo , Alfabetian. H.C. 2012. Aplikasi Teknologi Akuaponik Pada Budidaya Ikan Airtawar Dalam Meningkatkan Kapasitas Produksi . Jurnal Saintek Perikanan Vol 8 (1) :46-51.

Royce, Inkana. 2010. Integrated Culture of Ponds Fishes. Department of Animal Husbandary Otago Polytechnic. New Zealand.

Setiadi, E. 2014. Analisis Korelasi Media Tanam dengan Jumlah Serapan Amonia pada Sistem Resirkulasi Akuaponik. Direktorat Penelitian dan Pengembangan Kementrian Kelautan dan Perikanan. Jakarta. 